\title{
Numerical Simulation of Fluctuation Falling Film Absorption
}

\author{
He Mingyue ${ }^{1, a}$, Gao Hongtao ${ }^{1, b^{*}}$ \\ ${ }^{1}$ Institute of Refrigeration \& Cryogenics Engineering, Dalian Maritime University, Dalian, 116026, \\ China \\ aahemingyue@163.com, bgaohongtao@dlmu.edu.cn
}

Keywords: Falling Film; Absorption; Heat and Mass Transfer; Numerical Modeling.

Abstract. Based on the features of the falling film absorption, a CFD model of heat and mass transfer of falling film absorption in a vertical tube using $\mathrm{LiBr} / \mathrm{H}_{2} \mathrm{O}$ as working fluid was presented. The CFD model using the volume of fluid (VOF) method was presented for predicting the mass-transfer process of the two-phase parallel current falling film, in which a mass-transfer source term and a heat-transfer source term are given. By analyzing the computation results, the distributions of solution temperature and concentration at the interface and bulk are obtained. It also explores that the impact of film fluctuations on temperature and concentration of the interface and the influence of the fluctuation on the heat transfer between solution and cooling water.

\section{Introduction}

The $\mathrm{LiBr} / \mathrm{H}_{2} \mathrm{O}$ absorption heat pump or chiller is gaining global acceptance as one important technology for waste heat recovery ${ }^{[1]}$. So a better understanding is required of the combined heat and mass transfer process in absorption of $\mathrm{LiBr} / \mathrm{H}_{2} \mathrm{O}$, and many scholars have done some preliminary work.

Grigoréva and Nakoryakov ${ }^{[2]}$ and Grossman ${ }^{[3]}$ modeled and analyzed the absorption in laminar falling films using Fourier separation of variables techniques. They analytically solved the energy and species equations for the heat and mass transfer to a laminar falling film having constant temperature or adiabatic wall boundary condition. Van der Wekken and Wassenaar ${ }^{[4]}$ presented the heat transfer model to a constant temperature coolant, and use the coolant heat transfer coefficient as a variable to study the heat and mass transfer process. Habib and Wood ${ }^{[5]}$ formulated a model for concurrent absorption on a laminar, vertical film considering the heat and momentum transfer in the vapor phase. Yang and Wood ${ }^{[6]}$ numerically studied the case of inlet solution temperature different from the temperature of wall on laminar falling film absorption. Yigit ${ }^{[7]}$ investigated the falling film absorption on a vertical tube. In the aforementioned analysis most researchers assumed the constant physical properties. In the aforementioned analysis most researchers assumed the constant physical properties. Liu et al. ${ }^{[8]}$ researched on the momentum, heat and mass transfer of falling film absorption in a vacillating tube. Yoon et al. ${ }^{[9]}$ focused on the numerical study in absorption of vertical plate absorber which was cooled by water, and the temperature of cooling water is assumed to change linearly. Karami et al. ${ }^{[10][11]}$ studied the impact of the tilt angle on the absorption process. Goulet et al ${ }^{[12]}$ simulated lithium bromide solution fluctuating conditions falling film absorber.

The heat and mass transfer during the absorption process of water into $\mathrm{LiBr}$ solution is numerically simulated using CFD software-Fluent in present work. The practical convective boundary condition at the cooling water side is considered. The mass-transfer source term and a heat-transfer source term are given, which is theoretically supported by Fluent ${ }^{[13]}$.

\section{Governing equations and boundary conditions}

Physical models and basic assumptions

The system analyzed in the present study is depicted schematically in Fig.1. A film of liquid solution, composed of absorbent ( $\mathrm{LiBr}$ ) and absorbate (water), flows downward outside a vertical tube. $\mathrm{LiBr}$ solution always remains in the liquid phase, and steam is absorbed into the solution. The film is in contact with steam at constant pressure. Coolant usually flows countercurrent to the falling liquid film, 
and the integrated heat and mass transfer process occurs in the absorber as the falling film of strong solution absorbs steam. The $\mathrm{LiBr}$ solution has a vapor pressure lower than absorbate vapor pressure. As a result of this difference, absorption occurs. The water absorbed at the interface diffuses into the film. Simultaneously thermal effect associated with absorption boosts the liquid temperature near the interfacial region, improving the heat transfer within liquid film. Meanwhile, the liquid film is cooled by cooling water flowing outside the tube.

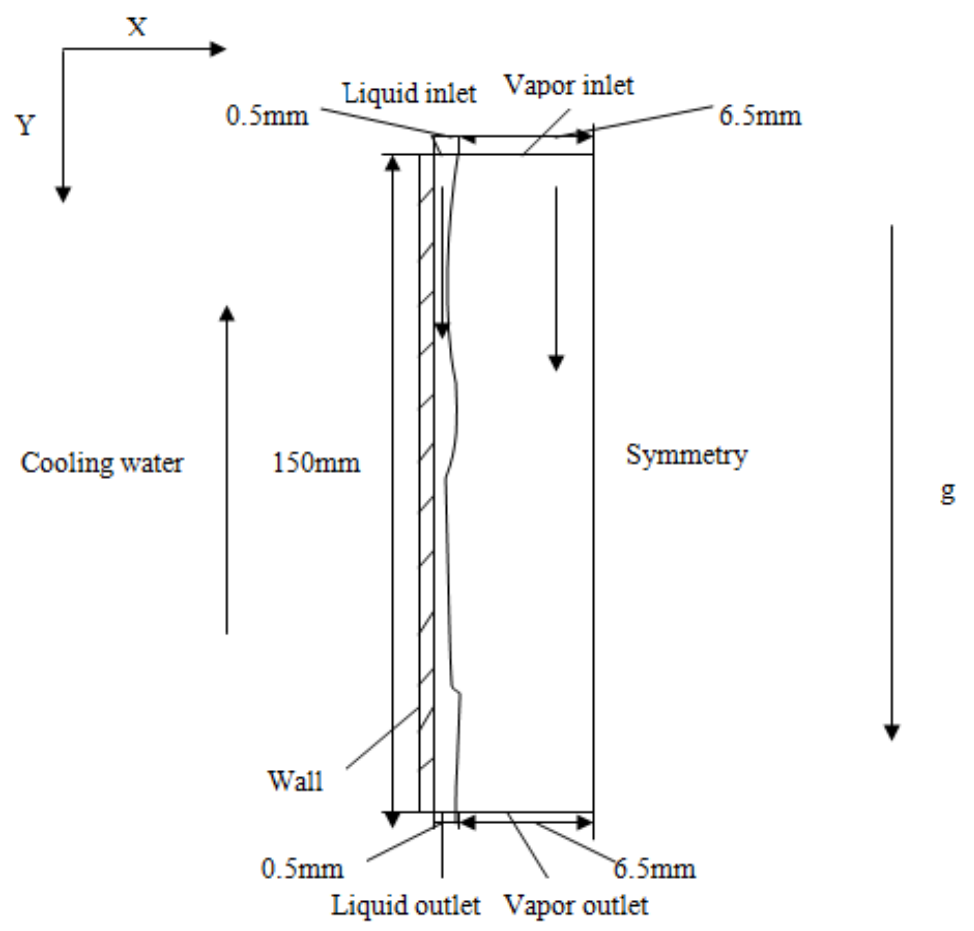

Fig.1. Schematic diagram of falling liquid film flow

The following assumptions are made in formulating the model:

(1) The physical properties of the liquid solution are constant and independent of temperature and concentration.

(2) Heat transfer in the vapor phase is negligible compared to that in the liquid phase.

(3) Liquid is postulated as Newtonian. Fluid flow is 2D laminar, full developed.

(4) No shear forces are exerted on the liquid by vapor.

(5) The cooling water is countercurrent with respect to the flow of liquid film and its temperature changes linearly.

(6) The coolant heat transfer coefficient remains constant. The thermal resistance of the solid wall is negligible.

Governing equations

For the flow model, the energy and diffusion equations could be described as follows:

$$
\begin{gathered}
\frac{\partial(\rho \mathrm{u})}{\partial \mathrm{x}}+\frac{\partial(\rho v)}{\partial y}=0 \\
u \frac{\partial C}{\partial \mathrm{x}}+v \frac{\partial C}{\partial y}=D\left(\frac{\partial^{2} \mathrm{C}}{\partial \mathrm{x}^{2}}+\frac{\partial^{2} \mathrm{C}}{\partial \mathrm{y}^{2}}\right)
\end{gathered}
$$

Boundary conditions

(1) At the entrance, the uniform liquid film temperature and concentration can be assumed, and $\mathrm{LiBr}$ solution is in thermodynamic equilibrium state:

$u=u_{0}=u_{i n}, T=T_{i n}, C=C_{i n}$.

(2) At the wall, it is impermeable, thus the gradient of concentration is equal to zero. For the wall temperature, the third boundary condition is given in term of coolant temperature and coolant heat 
transfer coefficient. The cooling water is countercurrent with respect to the flow of liquid film and its temperature changes linearly. The coolant heat transfer coefficient remains constant:

$u=v=0, \frac{\partial C}{\partial y}=0$.

(3) At the interface, the $\mathrm{LiBr}$ solution is in its saturation state. The local interfacial absorption heat flux is described as:

$C_{i}=C_{i}\left(T_{i}, P\right), m_{i}=-\rho D_{A B}\left(\frac{\partial C}{\partial y}\right), q_{i}=H_{a} m_{i}$.

(4) At the outlet, the type of outflow boundary condition is adopted, where the exit flow is assumed to be close to a fully developed condition

$\frac{\partial T}{\partial z}=0, \frac{\partial C}{\partial z}=0$

\section{Solution method and Operation conditions.}

The CFD software, Fluent, is used to simulate the heat and mass transfer in falling film absorption process. Fluent uses a control-volume-based technique to convert the governing equation to algebraic equations. Second order upwind discretization scheme is used to discredit the governing Esq. (1) and (2); $m_{l}$ and $q_{i}$ are given by UDF. In the present simulation, the film flowing distance is $150 \mathrm{~mm}$. Quadrilateral structured grid is selected as computing grid, and the grid number is 16000 . The convergence criterion for diffusion equation is $1 \times 10^{-3}$, and the convergence criterion for energy equation is $1 \times 10^{-6}$. And operation conditions are listd in table 1 :

Table 1 Operation conditions

\begin{tabular}{lc}
\hline Operating parameter & Values \\
\hline $\mathrm{C}_{1, \text { in }}$ & $60 \mathrm{wt} \%$ \\
$\mathrm{~T}_{1, \text { in }}$ & $46 \square$ \\
$\mathrm{T}_{0, \text { in }}$ & $32 \square$ \\
$\mathrm{T}_{0, \text { out }}$ & $36 \square$ \\
$\mathrm{P}$ & $1 \mathrm{kPa}$ \\
$\mathrm{d}_{\text {in }}$ & $14 \mathrm{~mm}$ \\
$\mathrm{~d}_{\text {out }}$ & $18 \mathrm{~mm}$ \\
$\mathrm{~L}$ & $150 \mathrm{~mm}$ \\
$\Gamma$ & $0.0758 \mathrm{~kg} /(\mathrm{m} \cdot \mathrm{s})$
\end{tabular}

\section{Results and discussion}

The gas-liquid interface concentration varies with the fluctuations film

Fig. 2 describes the film flowing down along the wall under the action of gravity.Because the solution continues to absorb steam, resulting in greater fluctuations of the film. Following the film fluctuations, interface concentration has sharp pulsations. This phenomenon can be explained by percolation theory: film fluctuations leads to increasing of fluid micelles transfer frequency between interface and the liquid body, resulting in dramatic changes in the concentration of the interface.So, it can be shown that film fluctuations can enhance interface concentration pulsation, which will strengthen the mass transfer between gas and liquid, improving mass transfer efficiency. 


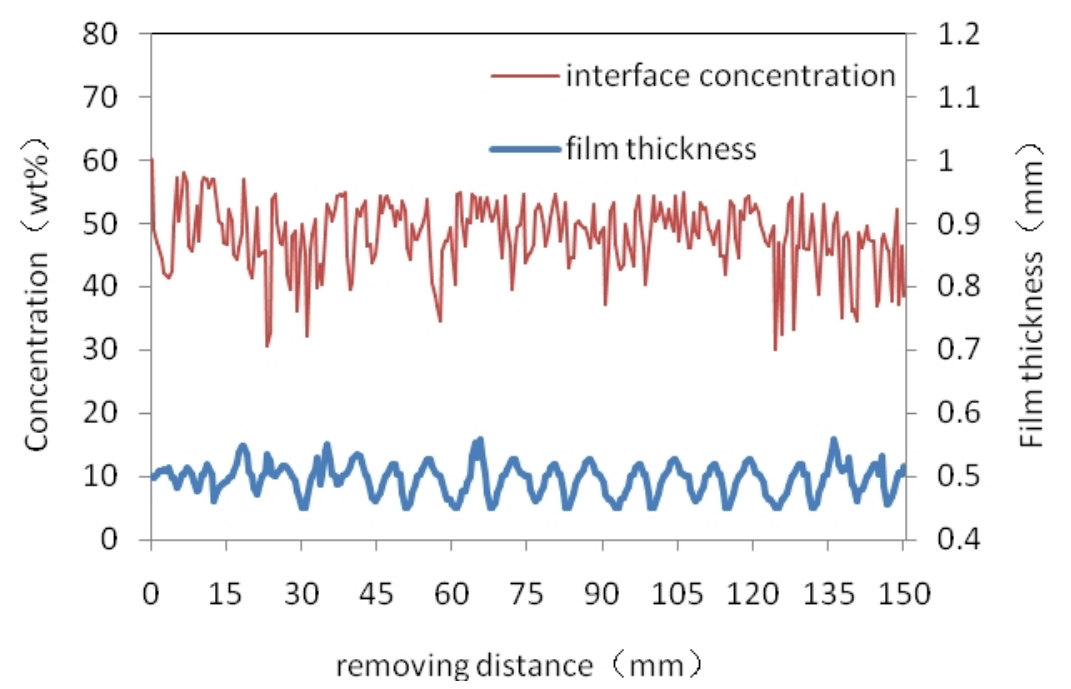

Fig.2. Variation of interface concentration and film thickness along downstream distance

The gas-liquid interface temperature varies with the concentration fluctuation

Interface temperature varing with concentrations is shown in Fig.3. While absorbing heat is released in the interface, but the temperature of the interface is in constant decrease because of the cooling effect of the cold water. Following interface concentration pulsation, interface temperature has a significant decline.It is because that film fluctuations make film uneven thickness, which is conducive to the cooling effect of cooling water.

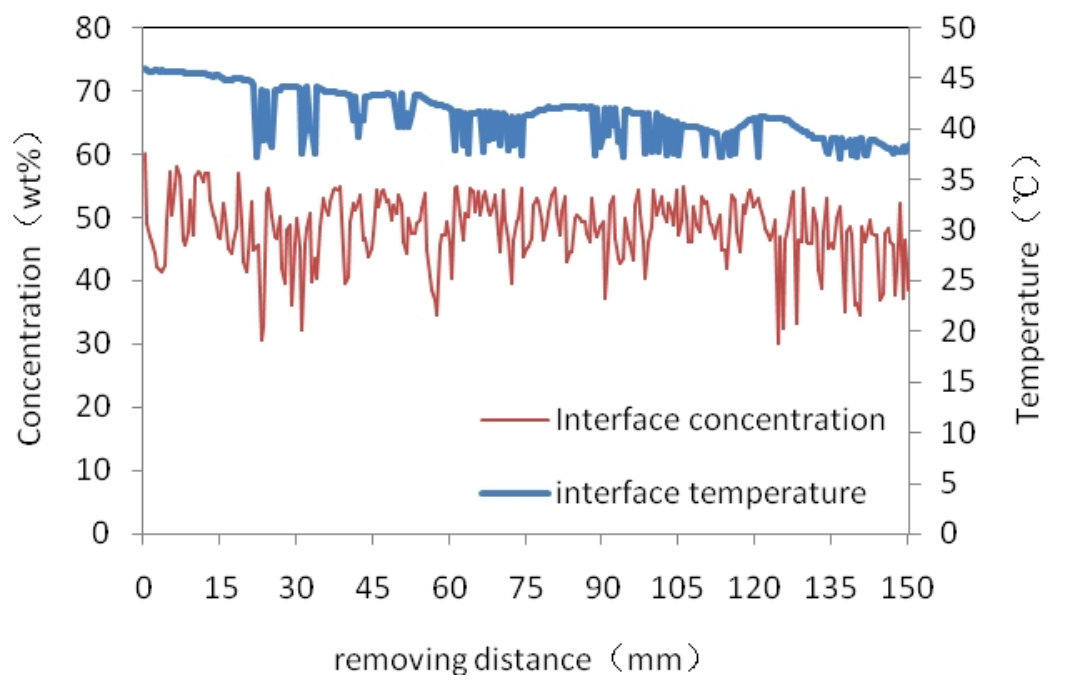

Fig.3. Variation of interface concentration and temperature along downstream distance

Bulk concentration and temperature varies

Fig. 4 shows the variation of typical temperature and concentration profiles with the downstream flowing distance. Initially, the changes of liquid temperature at interface, bulk and wall are remarkable near the entrance region, and decrease gradually. The interfacial concentration demonstrates the same trend with the bulk liquid temperature. The concentration at the wall remains constant equal to inlet concentration at small downstream location, and decreases slowly because of the mass diffusion of water. 


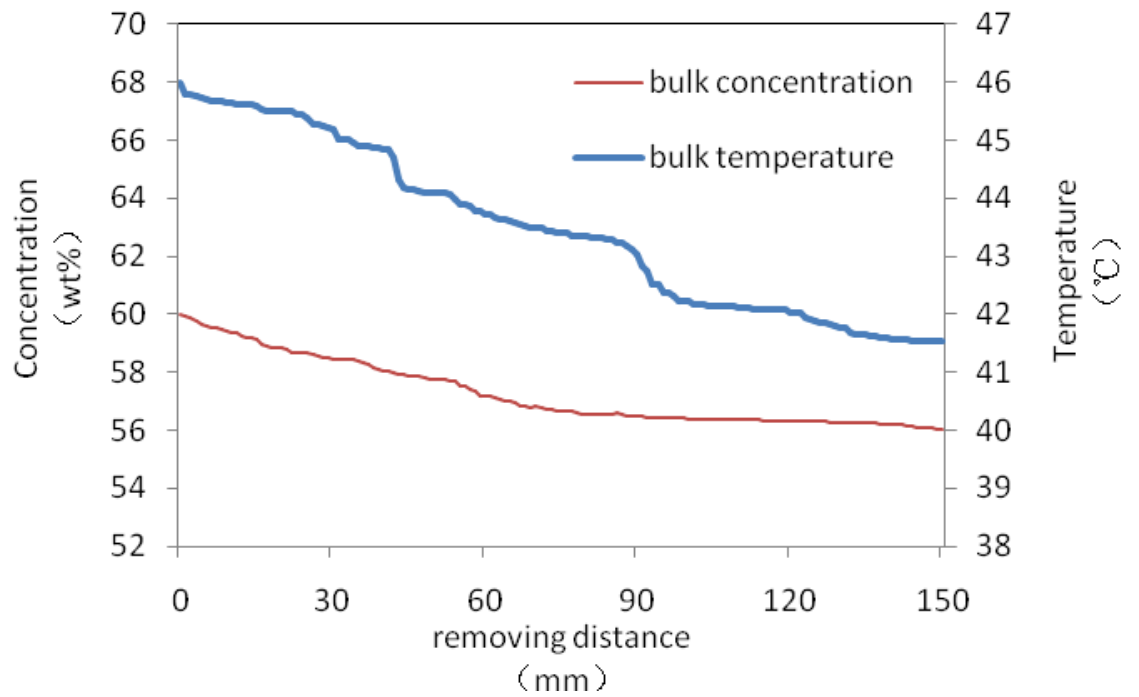

Fig.4 Bulk concentration and temperature profiles at different downstream positions

\section{Nomenclature}

\begin{tabular}{|c|c|}
\hline $\mathrm{C}$ & LiBr concentration (wt. \%) \\
\hline $\mathrm{C}_{\mathrm{p}}$ & specific heat $\left(\mathrm{J} \mathrm{kg}^{-1} \mathrm{~K}^{-1}\right)$ \\
\hline D & diffusion coefficient $\left(\mathrm{m}^{2} \mathrm{~s}^{-1}\right)$ \\
\hline $\mathrm{g}$ & gravitational acceleration $\left(\mathrm{m} \mathrm{s}^{-2}\right)$ \\
\hline $\mathrm{H}$ & enthalpy $\left(\mathrm{kJ} \mathrm{kg}^{-1}\right)$ \\
\hline $\mathrm{H}_{\mathrm{a}}$ & heat of absorption $\left(\mathrm{kJ} \mathrm{kg}^{-1}\right)$ \\
\hline $\mathrm{h}_{\mathrm{c}}$ & coolant heat transfer coefficient $\left(\mathrm{W} \mathrm{m}^{-2} \mathrm{~K}^{-1}\right)$ \\
\hline $\mathrm{k}$ & thermal conductivity $\left(\mathrm{W} \mathrm{m}^{-1} \mathrm{~K}^{-1}\right)$ \\
\hline $\mathrm{L}$ & plate height (m) \\
\hline $\mathrm{m}$ & mass flux $\left(\mathrm{kg} \mathrm{m}^{-2} \mathrm{~s}^{-1}\right)$ \\
\hline $\mathrm{P}$ & absorption pressure $(\mathrm{kPa})$ \\
\hline $\mathrm{q}$ & heat flux $\left(\mathrm{W} \mathrm{m}^{-2}\right)$ \\
\hline $\operatorname{Re}$ & Reynolds number \\
\hline $\mathrm{T}$ & temperature $\left(\mathrm{K}\right.$ or $\left.{ }^{\circ} \mathrm{C}\right)$ \\
\hline $\mathrm{u}$ & velocity in $\mathrm{x}$-direction $\left(\mathrm{m} \mathrm{s}^{-1}\right)$ \\
\hline $\mathrm{U}$ & average velocity $\left(\mathrm{m} \mathrm{s}^{-1}\right)$ \\
\hline $\mathrm{v}$ & velocity in y-direction $\left(\mathrm{m} \mathrm{s}^{-1}\right)$ \\
\hline \multicolumn{2}{|c|}{ Greek symbols } \\
\hline$\alpha$ & thermal diffusivity $\left(\mathrm{m}^{2} \mathrm{~s}^{-1}\right)$ \\
\hline 8 & liquid film thickness (m) \\
\hline$\mu$ & dynamic viscosity (Pa s) \\
\hline$\rho$ & density $\left(\mathrm{kg} \mathrm{m}^{-3}\right)$ \\
\hline$\Gamma$ & spray density $\left(\mathrm{kg} \mathrm{m}^{-1} \mathrm{~s}^{-1}\right)$ \\
\hline$\varepsilon$ & absorption coefficient \\
\hline
\end{tabular}




\section{Conclusions}

The combined heat and mass transfer during the absorption process of water into $\mathrm{LiBr}$ solution is numerically investigated using CFD software-Fluent in present work. The results obtained can be summarized as follows:

1) Film fluctuations have a significant impact on heat and mass transfer process of liquid film falling, which can promote the absorption.

2) The heat and mass transfer at the interface rises steeply after the inlet position, and then they start to decrease after reaching respective maximum values and decay gradually along the downstream distance.

3) Intensive heat transfer with cooling water by film fluctuations has an important role in improving performance of the absorber.

\section{Acknowledgements}

This work is financially supported by the Research funds of the Maritime Safety Administration of the People's Republic of China (2012_27), and the Fundamental Research Funds for the Central Universities (3132014338).

\section{References}

[1] J. D. Killion, S. A. Garimell. International Journal of Refrigeration, 24(8):755-797. (2001)

[2] N. I. Grigoréva, V. E. Nakoryakov. Eng. Phys. Thermophys, 33, 1349-1353. (1977)

[3] G. Grossman. Int. J. Heat Mass Transfer 26, 357-371. (1983)

[4] B. J. C. Van Der Wekken, R. H. Wassenaar. Int. J. Refrig. 11, 70-77. (1988)

[5] H. M. Habib, B. D. Wood, Simultaneous heat and mass transfer for a falling film absorber-the two phase flow problem, in: Sol. Energy Eng. Proceedings of the 12th Annual International Solar Energy Conference, ASME, 1990, pp. 61-67.

[6] R. Yang, B. D. Wood. Sol. Energy 48, 195-198. (1992)

[7] A. Yigit. Heat Mass Transfer 26, 269-278. (1999)

[8] Yanli Liu, Shiming Xu, Wei Han, et al. Fluid Machinery, 44(1):65-69. (2004) In Chinese

[9] J. I. Yoon, T. T. Phan, C.G. Moon, P. Bansal. Appl. Therm. Eng. 25, 2219-2235. (2005)

[10] S. Karami, B. Farhanieh. Heat and MassTransfer, 46(2):197-207. (2009)

[11] S. Karami, B. Farhanieh. Heat and Mass Transfer, 47(3):259-267. (2011)

[12] R. Goulet, R. Knikker, E. Heat and Mass Transfer, 50(2):285-300. (2014)

[13] Fluent Inc. Fluent user's guide; 2011. 